\title{
Cultural implications of filial obligation and the Asian Indian American family caregiver
}

\author{
Paula K. Baldwin, ${ }^{1}$ Natalie D. Pope, ${ }^{2}$ Adam D. Marks ${ }^{3}$ \\ ${ }^{1}$ Department of Communication Studies, Western Oregon University, Monmouth, OR; ${ }^{2}$ University of Kentucky, Lexington, KY; \\ ${ }^{3}$ Department of Internal Medicine, University of Michigan, Ann Arbor, MI, USA
}

\begin{abstract}
Family caregivers in young adulthood from different racial/ethnic groups represent an understudied population. Of this group, Asian Indians are a diverse and fast-growing immigrant population in the US and present unique challenges for health care providers. To illustrate factors influencing a young family caregiver from an under-represented racial/ethnic population, we report on the case of a 33 year-old American from an Asian Indian background who was a caregiver for his father with Normal Pressure Hydrocephalus (NPH). With this case report, we illustrate that medical providers should attend to cultural norms of the family system, including family communication patterns, filial obligation, and decision-making.
\end{abstract}

\section{Introduction}

Research shows that young people often assume caregiving responsibilities for chronically and terminally ill family members, yet these young caregivers (ages 18 to 40) are an under-researched population. ${ }^{1}$ Though caregiving research has focused primarily on caregivers in midlife, re-

Correspondence: Paula K. Baldwin, Department of Communication Studies, Western Oregon University, 345 Monmouth Avenue North, Monmouth, OR 97361, USA.

Tel: + 1.503.838.8065.

Email: baldwinp@wou.edu

Contributions: PKB, data collection and analysis, writer (60\%); NDP, data collection and analysis, writer $(30 \%)$; ADM, editor $(10 \%)$.

Conflict of interest: the authors declare no potential conflict of interest.

Note: this study is not funded and is excerpted from a larger study conducted by authors Baldwin and Pope. A version of this paper was presented as a poster at the International Palliative Care Network Conference, 2016

Key words: Family caregiver; Asian Indian; Filial obligation; Cultural norms.

Received for publication: 6 February 2017.

Revision received: 13 March 2017.

Accepted for publication: 23 March 2017.

This work is licensed under a Creative Commons Attribution NonCommercial 4.0 License (CC BY-NC 4.0).

CCopyright P.K. Baldwin et al., 2017

Licensee PAGEPress, Italy

Qualitative Research in Medicine \& Healthcare 2017; 1:39-43

doi:10.4081/qrmh.2017.6618 cent data from the National Alliance on Caregiving [NAC] and the AARP Public Policy Institute indicate that $24 \%$ of all caregivers are ages 18 to $34,23 \%$ are 35 to 49 , and $86 \%$ of those informal caregivers are relatives. ${ }^{2}$

In addition to age, we know that gender is also a deciding factor in terms of who takes on the caregiving in families. Although men can and do assume the role of caregiver, research shows that more often, women become caregivers, with approximately $60 \%$ of caregivers being female. ${ }^{2}$ However, due to shifts in social demographics, more men are becoming caregivers. ${ }^{2,3}$

While age and gender are important in understanding the experience of caring for relatives with chronic and terminal illness, caregivers' culture is also worthy of attention. Recent reports indicate that prevalence of caregiving varies by racial/ethnic group and is highest among Hispanics (21\%), followed by African Americans (20.3\%), Asian Americans (19.7\%), and Whites (Non-Hispanic) (16.9\%). ${ }^{2}$

Asians are a fast-growing and diverse minority group in the US and this case focuses on the experience of one family from South Asia. The 2010 Census reported 3.8 million South Asians living in the US and more than $80 \%$ of these South Asians are of Indian origin..$^{4,5}$ A critical, yet often overlooked factor impacting the relationship between the health care provider and the patient, caregiver and family is the family's culture. We believe that health care providers should embrace a more culturally bound view of caregiving, which offers valuable insights into a fuller spectrum of the caregiving experience. Attending to individuals' cultural background more fully allows health care providers to engage with and support family caregivers who differ in things like their reactions to caregiving, their attitudes towards clinical intervention and outside help, and their ways of coping with stress.

We conducted searches in EBSCOhost using a variety of terms and combinations. South Asian Indian plus care- 
giver yielded no academic journal article results. South Asian plus caregiver, and South Asian American plus caregiver each yielded one academic journal article. Our search using Indian American plus caregiver yielded only results focusing on First/Native Americans. Given the paucity of research on young, male, Asian Indian caregivers, this case report represents a small, but significant step in building literature to inform culturally responsive health care for this population. Of note, we collected the data for this case study as part of a larger project exploring the experiences of young adults in family caregiving roles. Further details from this larger project are available elsewhere. ${ }^{6}$

\section{Materials and Methods}

Ravi (pseudonym) was a 33-year-old Asian Indian caregiver who, along with his wife, lived with his parents in their home outside a major eastern metropolitan city. Ravi's sister, age 28 , resided a significant distance away, in the southeastern U.S. with her husband and children. In September 2015, Ravi gave verbal consent to be interviewed once via telephone using an interview guide. (Interviewed by NDP; see Appendix). We digitally recorded his interview and had it professionally transcribed, resulting in 47 pages of text. At the time of the interview, Ravi and his wife, age 32, were about to celebrate one year of marriage. Ravi's parents had been married for nearly 35 years. Ravi's mother had no health concerns, but she was limited in her ability to speak and understand English, and had always been dependent on her husband for functional tasks such as driving.

In 2012, at age 58, Ravi's father was diagnosed with early-onset Alzheimer's with an additional diagnosis of Parkinson's disease one year later. Ultimately, physicians diagnosed Ravi's father with Normal Pressure Hydrocephalus (NPH) and he required 24/7 care. Although Ravi admitted his dad had always had an aggressive streak, his behavior worsened as the NPH progressed. Consequences of his violent conduct were severe. Ravi's father was arrested multiple times for behaviors like entering other people's homes and urinating in public places. Ravi and his family were evicted two separate times and at one point, Ravi's father spent six months in a psychiatric facility and there was an open case with Adult Protective Services, which was initially opened after Ravi's dad physically attacked some neighbors and a police officer.

When it became apparent that his father needed caregiving that his mother was unable to provide, Ravi took FMLA for six months. Ravi quickly realized that the situation was worse than he expected and that the caregiving required was not temporary. Bound by cultural expectations, Ravi quit his full-time job about three years ago to care for his father. He has since started a consulting business to help meet the financial obligations of the family. Ravi's mother did not drive and although she spoke some English, she was not able to communicate comfortably with her husband's hospice and palliative care providers.

While Ravi reports spending about 80 hours a week providing hands-on help to his father, he minimized the care he provides. He described his 55 year-old mother as the primary caregiver, indicating she spends up to 168 hours per week caring for her husband. He expressed, There are months where she does not even leave the house. At this point in their caregiving journey, Ravi appeared more concerned with his mom than his dad. He admitted, Her life will be better after he's gone as she has been isolated from her local community, as well as her family of origin in India.

In the past year, Ravi's father's health continued to decline and at the time of this interview, he was receiving hospice and palliative care services. His father's weight had dropped to only 88 pounds, he was in a wheelchair full time, and he had lost the ability to speak.

From his role as a family caregiver, Ravi derived a meaningful part of his social identity and acknowledged many positive aspects of the experience. Ravi's familycentered cultural norms provided a context for his positive perceptions of helping care for his dad. By acting as translator for his mother, caregiver for his father despite their difficult relationship history, and providing financial stability for his parents, Ravi found satisfaction in fulfilling his expected role; it was in this way, that he honored his parents and his family.

\section{Results and Discussion}

Several factors in Ravi's situation are worth highlighting. First, his mother experienced linguistic isolation with her limited English proficiency, restricting interaction with her husband's health care providers and the medical community at large. Language proficiency has often been denoted as one indication of acculturation and Ravi's mother's limited medical literacy and inability to drive prevented her from being the sole caregiver for his dad with a serious medical condition. ${ }^{7}$ Often when only one member of a family speaks English, health care providers tend to focus their communication with that individual and can ignore the needs of other family members. Especially in care for chronically and terminally ill patients, efforts should be made to utilize interpreter services and/or cultural brokers so as to fully evaluate for any distress non-English-speaking family members may have.

Second, in contrast to traditional Western gender norms where daughters become caregivers to aging parents, in Asian Indian cultures, the oldest son is often the one who cares for parents. ${ }^{8}$ As Ravi explained, In our culture, [families] tend to stay together.... and it's not like a daughter has to be a caregiver. I think [sic] our culture, the son really has to step up and do it. In Ravi's case, his younger sister was geographically distant thus preventing her from assisting in her father's care. Caregiving by the eldest son can sometimes be only in name, with daugh- 
ters-in-law being the ones to provide the daily assistance, ${ }^{9}$ but in Ravi's situation, he had left full time employment and been caring for his father for about 18 months before he met and married his wife. During the time of our interview, however, Ravi remained at home with his parents while his wife worked full-time outside of the home.

Ravi exhibited a strong sense of filial obligation regarding his father's care, in spite of their relationship history. Ravi disclosed his father had a history of alcoholism and he was often aggressive: Sure, my dad used to beat people up...when I was little, he would beat me up, too. Even so, Ravi asserted that he was raised extremely well. $\mathrm{He}$ expressed a desire to reciprocate the love and sacrifice his parents gave in raising him. Throughout his life, Ravi had also observed his mother's own filial obligation: You see, she's here taking care of my dad. She [also] took care of his mother, my grandmother on my dad's side. In contrast to Ravi's strong sense of duty to care for his parents, he explicitly stated that he did not expect his children to maintain the same sense of filial duty. I tell my wife...I say, what we're doing for our parents today, we don't even expect a quarter from our kids down the line. Health care providers should be aware of cultural norms and validate, as in this case, the role of male family members in the caregiving of patients with chronic and terminal conditions.

Lastly, Ravi's parents were financially dependent on him and his wife. His mom had never worked outside the home and his dad has been retired for several years. Kalavar and Willigan suggested that when older immigrants lose their financial assets and material basis for power, they can be treated as dependent guests rather than patriarchs and matriarchs (p. 227), ${ }^{10}$ but in Ravi's family, his mother retained her status as the head of the family. As this is contrary to what would be found in American culture, Ravi's American friends have a difficult time understanding how it could be that he makes the money, he runs the household, and yet, his parents still make the decisions. Ravi navigated the health care system, but still asserted that his mother was the boss and the final decision-maker. For South Asian families, where the culture depends heavily on filial obligation, as the son, Ravi may participate in health care discussions and subsequent decisions, but in the end, the ultimate outcome of the discussion is based on his mother's opinion. Again, health care providers need to have a keen awareness of this cultural dynamic, which can affect not only medical decision-making but also decisions about finances, funeral plans, and grief management.

\section{Conclusions}

Among all ethnic minority populations, satisfaction with health care in the US is lowest among Asians. ${ }^{11-14}$ One study of employer-based health insurance $(160,694$ participants: $83 \%$ White, $8 \%$ Black, $6 \%$ Hispanic, 3\% Asian) sought to measure satisfaction with health care by soliciting answers in these domains: receiving needed care; receiving care quickly; doctor communication; helpfulness of office staff; and customer service. ${ }^{11}$ Blacks, Hispanics and Asians reported lack of satisfaction with different aspects of their health care. Asians had significantly worse experiences, rated their care and their doctors lower, and reported more issues with access to healthcare compared to White participants. ${ }^{11}$ From the doctors' perspective, barriers to having effective end of life conversations with diverse populations include cultural differences in truth-telling and decision-making, and while the reasons for this are varied, one important component is the impact of culture on health and caregiving. Maintenance of the patriarchal or in this case, matriarchal, organization of this family, along with the cultural expectations of filial obligation during caregiving, offers an important communication insight for health care professionals and the medical community. Cultures offer different perspectives in areas such as communication, gender roles, organization of care, and decision-making. ${ }^{15}$ When interacting with health care providers, lack of awareness of and attention to these cultural differences can create additional stress for already highly strained caregiver. ${ }^{15}$ Resources that exist to help health care professionals build cultural awareness, especially self-awareness, include Exploring One's Community Map, ${ }^{16,17}$ the Iceberg Analogy, ${ }^{16}$ and Cox Pie Charts. ${ }^{18}$

In Ravi's case, although Ravi claimed his mother took the lion's share of caregiving for his father, it could also be speculated that in order to maintain his mother's position as the matriarch of the family, Ravi downplayed his contributions. While medical providers may communicate most comfortably with a family member such as Ravi, the most fluent English speaker, research has shown that this type of communication can be problematic. ${ }^{19}$ Professionals could benefit from cultivating an awareness of and acknowledgement of cultural norms in the organizational structure of the South Asian family. In end of life care, Periyakoil and colleagues found that limited knowledge of patients' cultures resulted in doctors' (i) inability to empathize with the ethnic patients' cultural values that influence [end of life] decisions, and (ii) committing cultural faux pas by discussing taboo topics which inadvertently offended the patient/ family and undermined the therapeutic relationships (p. 9). ${ }^{20} \mathrm{~A}$ general knowledge of patients' culture is not enough however, health care providers should inquire of individual caregivers concerning their decision-making processes and preferences and try to accommodate these preferences. Through this type of partnership building, caregiver burden can be reduced and/or improved. ${ }^{21}$ In Ravi's case, although he was the most accessible family member due to his English fluency, he was not the primary decision-maker. As his father's behavior spiraled out of control, not being the decision-maker created additional stress for Ravi and it would have been advantageous to have this type of part- 
nership support available to him through his health care providers. ${ }^{21}$

In the American medical model, the primary supposition is that the individual is responsible for the management of his or her own health care decisions. ${ }^{22}$ However, to work effectively with families of individuals with chronic or terminal illness, particularly those whose culture differs your own, we maintain that health care providers should consider three strategies. One, health care professionals must strive to build an effective rapport in order to join the family system by familiarizing themselves with and then accommodate themselves to the social rules of the culture. ${ }^{23} \mathrm{Sec}-$ ond, care providers must seek to understand the family hierarchy structure and determine who is (are) the decisionmaker(s) in order to jointly share the decision-making process between physicians and other health care providers and the patient and family. ${ }^{24}$ Ravi described his mother as the mouthpiece of the family and although he helped make decisions on behalf of his father, he denied having the authority to make the final call. He said, When we deploy a message to somebody, if there's a last call, or if there's a decision, I don't think I have the authority to say it. My mother will say it. While matriarchal family structure will not be the case for all South Asian patients, providers must attempt to provide individualized care to accommodate unique preferences and needs. After gaining the family's trust and identifying the decision-makers, the final step involves making sure that medical providers ask the appropriate questions to obtain the desired response to facilitate the best care options, ${ }^{25}$ as all the decision-making will be informed by the family's cultural beliefs. ${ }^{26}$ Mnemonic tools such as ETHNIC(S) (Explanation, Treatment, Healers, Negotiate, Intervention, Collaborate, Spirituality) can help medical providers understand how the patient's culture might affect their desires for treatment preferences at the end life, ${ }^{27}$ and can help health care providers more intentionally attend to issues of culture throughout the treatment process to help foster trust with the patient and his or her family.

Communicating cross-culturally can be challenging, but not impossible. At its essence, intercultural communication is based on understanding the values, or what is good, desirable, or beautiful, in a culture as well as the norms or rules and expectations that instruct people's behavior within a culture. ${ }^{28}$ This lack of attention to culture in health care interactions has been documented extensively in journal articles such as ours and books such as The Spirit Catches You and You Fall Down (TSCYAYFD) published in $1997 .{ }^{29}$ It says something about our attention to this problem that twenty years later, academic scholars are still writing and publishing about the importance of intercultural training for health care providers. In TSCYAYFD, Lia, a young Hmong child, was the center of a perfect storm of the Hmong culture, the medical staff that treated Lia, and the American medical culture. Once Lia was diagnosed with epilepsy, she became the center of an expressed struggle between her parents who preferred a combination of folk remedies and Western medicine and her physicians whose preferred treatment was a large assortment of pharmacology. ${ }^{29}$ These profound cultural differences and miscommunication exacerbated the dissension between Lia's parents and her physicians, resulting in Lia losing all her higher brain functions at age four. ${ }^{29,30}$ At the time this book was published, it received lots of attention from the medical community, ${ }^{30}$ but have they really taken the lessons learned to heart or better yet, to the medical classroom? If health care providers were trained to interact with different cultures appropriately, Ravi, his mother, and his father's experiences might have been very different.

We recommend that physicians and other medical providers should strive to employ appropriate interpersonal communication skills, undertake formal training in intercultural communication and/or employ interpreters or cultural brokers, and focus on appropriate clinical questions to elicit the most accurate responses from the patient and family. Use of the strategies mentioned furthers the creation of a solid foundation based on mutual trust and respect between the health care provider, patient, and family caregiver, thereby laying the groundwork for a more meaningful relationship. ${ }^{31}$ Implementing these strategies should serve to strengthen the interaction between the health care system and caregivers, such as Ravi, and ultimately, serve the needs of the patient more effectively.

\section{References}

1. Levine C, Hunt GG, Halper D, et al. Young adult caregivers: A first look at an understudied population. Am J Public Health 2005;95:2071-75.

2. National Alliance for Caregiving and AARP Public Policy Institute. Caregiving in the U.S. Washington, DC: National Alliance for Caregiving and AARP; 2015. Available from: http://www.caregiving.org/caregiving2015/

3. Robinson CA, Bottorff JL, Pesut B, et al. The male face of caregiving: A scoping review of men caring for a person with dementia. Am J Mens Health, 2014;8:409-26.

4. South Asian American Leading Together. A demographic snapshot of South Asians in the United States; 2012. Available from: http://saalt.org/wp-content/uploads/2012/09/Demographic-Snapshot-Asian-American-Foundation-2012.pdf

5. United States Census Bureau. The Asian population: 2010; 2012. Available from: http://www.census.gov/prod/cen2010/ briefs/c2010br-11.pdf

6. Pope ND, Baldwin P. Life interrupted: Young adults as family caregivers. Gerontol 2015;55:740.

7. Diwan S, Jonnalagadda SS, Balaswamy S. Resources predicting positive and negative affect during the experience of stress: A study of older Asian Indian immigrants in the United States. Gerontol 2014;44:605-14.

8. Sharma RK, Khosla N, Tulsky JA, Carrese JA. Traditional expectations versus US realities: First- and second-generation Asian Indian perspectives on end-of-life care. J Gen Intern Med 2011;27:311-7.

9. Lee M, Yoon E, Kropf N. Factors affecting burden of South 
Koreans providing care to disabled older family members. Inter J Aging Soc Develop 2007;64:245-62.

10. Kalavar JM, Willigan JV. Older Asian Indians resettled in America: Narratives about households, culture and generation. J Cross Cult Gerontol 2005;20:213-30.

11. Lurie N, Zhan C, Sangl J, et al. Variation in racial and ethnic differences in consumer assessments of health care. Amer J Man Care 2003;9:502-9.

12. Murray-Garcia JL, Selby JV, Schmittdiel J, et al. Racial and ethnic differences in a patient survey: patients' values, ratings, and reports regarding physician primary care performance in a large health maintenance organization. Med Care 2000;38:300-10.

13. Siu AL. Variation and quality of self-report health data: Asian and Pacific Islanders compared with other ethnic groups. Med Care 1995;33:1120-31.

14. Taira D, Safran D, Seto T, et al. Asian American patient ratings of physician primary care performance. J Gen Intern Med 1997;12:237-42.

15. Van Keer R, Deschepper R, Huyghens L, et al. Dealing with cultural diversity during the process of communication and decision-making in the ICU: A literature review. Crit Care 2014;18(S1):24.

16. Health Resources and Services Administration. Transforming the face of health professions through cultural and linguistic competence education: The role of the HRSA Centers of Excellence; 2002. Available from: http://www. hrsa.gov/culturalcompetence/cultcompedu.pdf

17. Pinderhughes E. Understanding race, ethnicity, and power: The key to efficacy in clinical practice. New York: Free Press; 1989.

18. Cox T. Cultural diversity in organization: Theory, research, and practice. San Francisco, CA: Berrett-Koehler Publishers, Inc.; 1994.

19. Eli K. Social networks, social support and coping with serious illness: The family connection. Soc Sci Med 1996;42:173-83.

20. Periyakoil VS, Neri E, Kraemer H. No easy talk: A mixed methods study of doctor reported barriers to conducting ef- fective end-of-life conversations with diverse patients. PLoS One 2015;10:e122321.

21. Brodaty H, Donkin M. Family caregivers of people with dementia. Dialogues Clin Neurosci 2009;11:217-28.

22. Villaruel AM, Portillo CJ, Kane P. Communicating with limited English proficiency persons: Implications for nursing practice. Nurs Outlook 1999;47:262-70.

23. Dysart-Gale, D. Clinicians and medical interpreters: Negotiating culturally appropriate care for patients with limited English ability. Fam Comm Hlth 2007;30:237-46.

24. Gravel K, Légaré F, Graham ID. Barriers and facilitators to implementing shared decision-making in clinical practice: a systematic review of health professionals' perceptions. Implement Sci, 2006;1:16.

25. Carteret M. Eliciting quality patient response in cross-cultural care. Cross-cultural communications for health care professional; 2011. Available from: http://www.dimensionsofculture.com/2011/03/eliciting-quality-patient-responsesin-cross-cultural-care/

26. Wright AA, Stieglitz H, Kupersztoch YM, et al. United States Acculturation and Cancer Patients' End-of-Life Care. PLoS One 2013;8:e58663.

27. Levin S, Like R, Gottlieb J. ETHNIC: A framework for culturally competent clinical practice; 2000. New Brunswick, NJ: Department of Family Medicine, UMDNK-Robert Wood Johnson Medical School.

28. Floyd K. Culture and Gender. In Interpersonal Communication (pp. 36-43); 2011. New York: McGraw-Hill Education.

29. Fadiman, Anne. Spirit Catches You And You Fall Down. 1997. New York: Farrar, Straus and Giroux.

30. Fox, M. Lia Lee dies; Life went on around her, redefining care. The New York Times. 2012. Available from: http://www.nytimes.com/2012/09/15/us/life-went-onaround-her-redefining-care-by-bridging-a-divide.html

31. Doehring C. Intercultural care: Trust and theological accountability. In the practice of pastoral care, revised and expanded edition (pp. 1-36); 2014. Westminster John Knox Press. 